\title{
Iron(II) tetrakis(diaquaplatinum)octacarboxyphthalocyanine supported on multi-walled carbon nanotube platform: an efficient functional material for enhancing electron transfer kinetics and electrocatalytic oxidation of formic acid
}

\author{
Solomon A. Mamuru, ${ }^{a}$ Kenneth I. Ozoemena, ${ }^{* a b}$ Takamitsu Fukuda ${ }^{c}$ and Nagao Kobayashi ${ }^{d}$ \\ Received 9th July 2010, Accepted 8th September 2010 \\ DOI: 10.1039/c0jm02210a \\ A novel platinum-based macrocycle, iron(II) tetrakis(diaquaplatinum)octacarboxyphthalocyanine \\ $(\mathrm{PtFeOCPc})$, was synthesised and characterised. The heterogeneous electron transfer and \\ electrocatalytic properties of this functional material towards the oxidation of formic acid have been \\ explored on a graphite electrode platform pre-modified with or without acid-functionalised multi- \\ walled carbon nanotubes (MWCNTs). We prove that PtFeOCPc supported on a MWCNT platform \\ (MWCNT-PtFeOCPc) exhibits enhanced electrochemical response in terms of (i) electron transfer \\ towards outer-sphere redox probe, (ii) catalytic rate constant, and (iii) tolerance towards $\mathrm{CO}$ poisoning \\ during formic acid oxidation. The results clearly suggest that the MWCNT-PtFeOCPc is a promising \\ platform for potential application as an electrocatalyst for direct formic acid fuel cell.
}

\section{Introduction}

Metallophthalocyanines (MPcs) have continued to be one of the most studied classes of macrocyclic organometallic functional materials. They exhibit remarkable redox ${ }^{1-4}$ and physico-chemical properties that are of interest in fundamental and applied research fields such as electrocatalysis and sensing, ${ }^{1,5-9}$ electrochromic and electroluminescent display devices, ${ }^{\mathbf{1 0}}$ liquid crystal display devices, ${ }^{11}$ photodynamic therapy ${ }^{12}$ and other photosensitisation processes, ${ }^{13-16}$ and in the development of energy storage and conversion systems such as fuel cells, ${ }^{17}$ oxygen reduction reaction, ${ }^{18-21}$ lithium ion battery, ${ }^{22,23}$ and supercapacitor development. ${ }^{24-26}$ The importance of MPc complexes in these technologically important applications has remained the major motivation for the intense search for novel MPc complexes. In the area of electrocatalysis and energy storage and conversion systems, the use of transition metal phthalocyanine complexes is crucial. In this work, we report the synthesis of new iron phthalocyanine complex peripherally substituted with platinum, iron(II) tetrakis(diaquaplatinum)octacarboxyphthalocyanine $\left(\mathrm{C}_{40} \mathrm{H}_{24} \mathrm{~N}_{8} \mathrm{FeO}_{24} \mathrm{Pt}_{4}\right.$, herein referred to as PtFeOCPc, Scheme 1), and interrogate its electrocatalytic properties towards the oxidation of formic acid, a well-known small organic molecule for fuel cell development.

Considering that many potential applications of the transition metal MPc complexes, for example in energy systems and

${ }^{a}$ Department of Chemistry, University of Pretoria, Pretoria, 0002, South Africa. E-mail: kozoemena@csir.co.za; Fax: +27 12841 2135; Tel: +27 128413664

${ }^{b}$ Energy and Processes Unit, Materials Science and Manufacturing, Council for Scientific \& Industrial Research (CSIR), Pretoria, 0001, South Africa

'Department of Chemistry, Graduate School of Science, Osaka University, 1-1 Machikaneyama, Toyonaka Osaka, 560-0043, Japan

${ }^{d}$ Department of Chemistry, Graduate School of Science, Tohoku University, Sendai, 980-8578, Japan heterogeneous catalysis, involve the use of their thin solid films and exchange of electrons between the solid/electrolyte interface, some understanding of the heterogeneous electron transfer (HET) kinetics is important. Thus in this work we also explored the HET kinetics of the PtFeOCPc when supported onto multiwalled carbon nanotube (MWCNT)-based electrode. Our choice for MWCNT-based electrode is motivated by literature precedents on the ability of carbon nanotubes to enhance the electrochemical performance of the MPc complexes. ${ }^{24-29}$

Research into formic acid (FA) has received great attention and has been considered as a replacement candidate for methanol as fuel in fuel cells. This is due to its high electrochemical activity arising from its non-toxicity, non-flammability and its ability to facilitate the transport of proton within the anode catalyst. ${ }^{30-33}$ Because of its advantages over methanol, a direct formic acid fuel cell (DFAFC) is being gradually recognised as a promising power source. ${ }^{34}$ Platinum is one of the most frequently used catalyst for formic acid oxidation, ${ }^{30-35}$ however, studies have shown that practical applicability is inadequate because the electro-oxidation process on a platinum $\left(\mathrm{Pt}^{0}\right)$ catalyst surface could occur through two parallel pathways, the "direct pathway" and the "carbon monoxide (CO) pathway". In the direct pathway which is preferred, the formic acid is oxidized directly to $\mathrm{CO}_{2}$ :

$$
\mathrm{HCOOH}+\mathrm{Pt}^{0} \rightarrow \mathrm{X} \rightarrow \mathrm{CO}_{2}+2 \mathrm{H}^{+}+2 \mathrm{e}^{-}
$$

where $\mathrm{X}$ is an active intermediate with relatively short lifetimes. ${ }^{36}$ In the "CO pathway", the formic acid is oxidized slowly forming a poisoning intermediate $\left(\mathrm{CO}_{\mathrm{ad}}\right)$ before the end product $\mathrm{CO}_{2}$ is yielded.

$$
\begin{gathered}
\mathrm{HCOOH}+\mathrm{Pt}^{0} \rightarrow \mathrm{Pt}-\mathrm{CO}+\mathrm{H}_{2} \mathrm{O} \\
\mathrm{Pt}^{0}+\mathrm{H}_{2} \mathrm{O} \rightarrow \mathrm{Pt}-\mathrm{OH}+\mathrm{H}^{+}+\mathrm{e}^{-}
\end{gathered}
$$




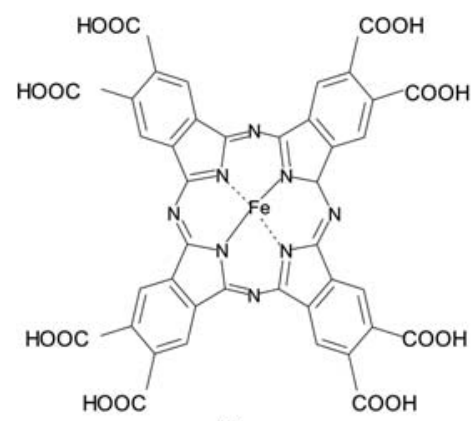

(I)

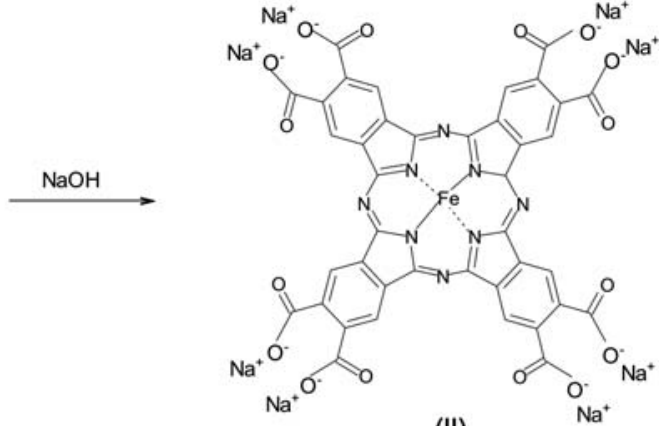

(II)

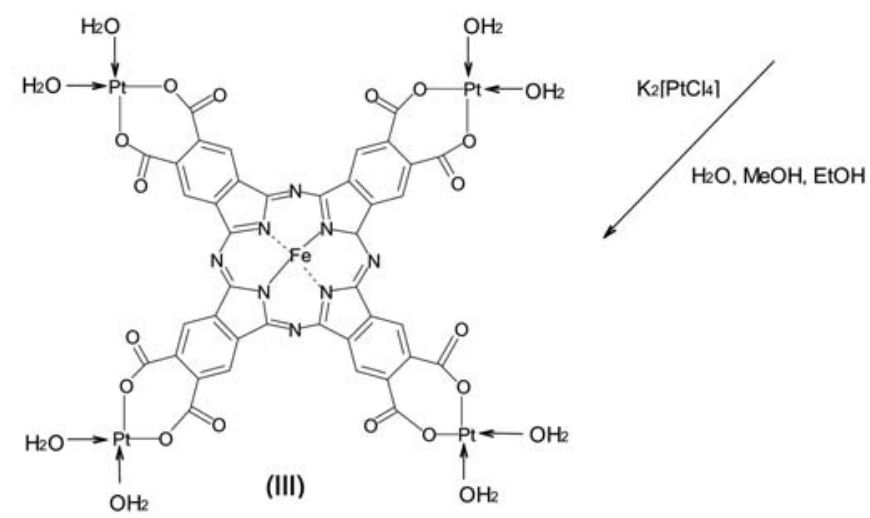

Scheme 1 Schematic pathway for the synthesis of iron(II) tetrakis(diaquaplatinum)octacarboxyphthalocyanine $\left(\mathrm{C}_{40} \mathrm{H}_{24} \mathrm{~N}_{8} \mathrm{FeO}_{24} \mathrm{Pt}_{4}\right)$.

$$
\begin{gathered}
\mathrm{Pt}-\mathrm{CO}+\mathrm{Pt}-\mathrm{OH} \rightarrow 2 \mathrm{Pt}^{0}+\mathrm{CO}_{2}+\mathrm{H}^{+}+\mathrm{e}^{-} \\
\text {Overall: } \mathrm{HCOOH} \rightarrow \mathrm{CO}_{2}+2 \mathrm{H}^{+}+2 \mathrm{e}^{-}
\end{gathered}
$$

The $\mathrm{CO}_{\mathrm{ad}}$ intermediate formed in the $\mathrm{CO}$ pathway can be strongly adsorbed on the surface of the $\mathrm{Pt}$, thereby poisoning the catalyst, hence not desirable. Unfortunately, various studies indicate that the electro-oxidation on common Pt catalysts occurs mainly through the CO pathway. ${ }^{37,38}$ In order to lead the reaction to the desired "direct pathway", Pt-based bimetallic catalysts (Pt-M) such as $\mathrm{PtSb},{ }^{38} \mathrm{PtBi},{ }^{39} \mathrm{PtPb},{ }^{40} \mathrm{PtRu},{ }^{41} \mathrm{PtIr},{ }^{42}$ $\mathrm{PtTe}^{43}$ and $\mathrm{PtAu}^{44}$ were proposed. It was found that bimetallic catalysts performed much better than pure Pt catalyst. ${ }^{37-44}$

On the other hand, the use of Pt catalyst integrated with metal macrocyclic compounds (such as MPc) for the oxidation of formic acid is virtually unknown. The only closest work in this area is the recent work by Zhou et $\mathrm{al} . .^{45}$ who carried out the electro-oxidation of formic acid using a bulk Pt disc electrode modified with watersoluble iron(II) tetrasulfophthalocyanine (FeTSPc) complex. The obvious disadvantages of such system include: (i) the high cost of Pt bulk metal support and (ii) the high probability of the immobilised FeTSPc to be easily washed off from the electrode during operation due to its high solubility in aqueous solution. Therefore, it is important to explore low-content Pt systems that contain FePc complexes that are not water-soluble (hydrophobic system) and supported on a low-cost carbon electrode substrate. In this work, we show that hydrophobic $\mathrm{PtFeOCPc}$ can serve as a potential electrocatalyst for the oxidation of formic acid in acidic medium. In addition, our result clearly reveals that $\mathrm{PtFeOCPc}$ supported on MWCNTs shows an appreciable level of tolerance to carbon monoxide $(\mathrm{CO})$ poisoning during formic acid oxidation.

\section{Experimental}

\subsection{Materials and reagents}

Potassium hexacyanoferrate(II) was obtained from B. Jones Ltd, South Africa, potassium hexacyanoferrate(III) was purchased from Bio-Zone Chemicals, South Africa. Potassium chloride, sulfuric acid and formic acid were obtained from Merck, potassium tetrachloroplatinate was obtained from the British Drug House (BDH). The iron(II) octacarboxyphthalocyanine (FeOCPc) was prepared by adopting a similar procedure described for its cobalt derivative ${ }^{46}$ Briefly, in a two-neck flask equipped with a reflux condenser and a thermometer was added $2.50 \mathrm{~g}(11.5 \mathrm{mmol})$ of pyromellitic dianhydride, $13.0 \mathrm{~g}(0.22 \mathrm{mmol})$ of urea, $23.5 \mathrm{mmol}$ of $\mathrm{FeCl}_{2}$, and $0.1 \mathrm{~g}(0.65 \mathrm{mmol})$ of 1,8-diazacyclo [5.4.0] undec-7-ene (DBU). The flask was heated to $250^{\circ} \mathrm{C}$ until the reaction mixture was fused. The reaction product was washed with water, acetone and $6 \mathrm{M}$ hydrochloric acid $(\mathrm{HCl})$. After being dried, the solid obtained was hydrolyzed. $30 \mathrm{~g}$ of crude product, $30 \mathrm{~g}$ of potassium hydroxide $(\mathrm{KOH})$ and $90 \mathrm{~mL}$ of water were charged into a $300 \mathrm{~mL}$ beaker. The beaker was heated for $480 \mathrm{~min}$ at $100^{\circ} \mathrm{C}$. The mixture was diluted with $200 \mathrm{~mL}$ water and was filtered. The filtrate was acidified to $\mathrm{pH} 2$ with concentrated $\mathrm{HCl}$. The product precipitated as a green solid at this point. The green product was separated from the solution by a centrifuge. The solid was further dissolved in $\mathrm{NaOH}$ and subjected to column chromatography using alumina bed with $\mathrm{NaOH}$ solution as an eluant. The eluant was acidified as before to precipitate the solid product via centrifugation and dried, yield: $30 \%$. Calculated for $\mathrm{C}_{88} \mathrm{H}_{128} \mathrm{~N}_{8} \mathrm{H}_{16} \mathrm{Fe}$ : C 70.87, $\mathrm{H} 8.63, \mathrm{~N}$ $7.51 \%$. Found: C 70.18, H 8.40, N 7.43\%. $\lambda_{\max }$ (pyridine) $/ \mathrm{nm}$ : 684.0. $\nu_{\text {max }} / \mathrm{cm}^{-1}: 3300(\nu \mathrm{C}-\mathrm{H}), 2900(\nu \mathrm{C}-\mathrm{H}), 1590(\nu \mathrm{C}-\mathrm{C}), 1150$ $(\nu \mathrm{C}-\mathrm{C}), 1150(\delta \mathrm{C}-\mathrm{O}), 1090(\delta \mathrm{C}-\mathrm{H})$. 
Pristine MWCNTs (95\% pure, $15 \pm 5 \mathrm{~nm}$ diameter, 5-20 micron in length) were purchased from NanoLab (USA), and purified as before. ${ }^{47}$ Briefly, $1 \mathrm{~g}$ of MWCNTs was added to $140 \mathrm{~mL}$ of $2.6 \mathrm{M}$ $\mathrm{HNO}_{3}$, and the mixture was refluxed for $48 \mathrm{~h}$. The carbon nanotube sediment was separated by centrifugation, and washed with distilled water. It was then sonicated in a concentrated mixture of $\mathrm{H}_{2} \mathrm{SO}_{4}$ and $\mathrm{HNO}_{3}\left(3: 1\right.$ ratio) at $40{ }^{\circ} \mathrm{C}$ for $24 \mathrm{~h}$. The sediment was thereafter washed with distilled water, stirred for $30 \mathrm{~min}$ in a $4: 1$ $\mathrm{H}_{2} \mathrm{SO}_{4} / \mathrm{H}_{2} \mathrm{O}_{2}$ mixture at $70{ }^{\circ} \mathrm{C}$, and washed with distilled water. The final purified and functionalised MWCNT slurry was then oven-dried at $50{ }^{\circ} \mathrm{C}$ for $48 \mathrm{~h}$.

$N, N$-Dimethyl formamide, DMF, was purchased from SigmaAldrich, and was distilled and dried before use; formic acid (FA) was obtained from Sigma Aldrich. Carbon monoxide (CO) was supplied by Air Liquide (Pty) Ltd (South Africa). Ultra pure water (resistivity: $18.2 \mathrm{M} \Omega \mathrm{cm}$ ) was obtained from a Milli-Q water system (Millipore Corp., Bedford, MA, USA). All other reagents were of analytical grade and were used as received from the suppliers without further purification.

\subsection{Preparation of iron(II) tetrakis(diaquaplatinum)octacarboxyphthalocyanine $\left(\mathrm{C}_{40} \mathrm{H}_{24} \mathrm{~N}_{8} \mathrm{FeO}_{24} \mathrm{Pt}_{4}\right)$}

Step 1: the iron(II) tetrakis(diaquaplatinum)octacarboxyphthalocyanine $(\mathrm{PtFeOCPc})$ (III) was synthesised by adopting the same strategy reported for the cobalt derivative by Dolotova and Kaliya, ${ }^{48}$ (Scheme 1). Briefly, the sodium salt of iron(II) octacarboxyphthalocyanine (II) $(0.10 \mathrm{~g})$ was dissolved in distilled water $(12 \mathrm{~mL})$ and methanol $(106 \mathrm{~mL})$, potassium tetrachloroplatinate $(0.12 \mathrm{~g}, 0.28 \mathrm{mmol})$ dissolved in $50 \%$ ethanol $(190 \mathrm{~mL})$ was added to the solution of II and stirred for $3 \mathrm{~h}$ at room temperature. The resultant precipitate was filtered off after $48 \mathrm{~h}$, washed with distilled water and allowed to dry (yield: $0.10 \mathrm{~g}, 0.24 \mathrm{mmol}$ ).

Step 2: potassium tetrachloroplatinate $(0.10 \mathrm{~g}, 0.24 \mathrm{mmol})$ dissolved in $50 \%$ ethanol $(119 \mathrm{~mL})$ was added to the suspension of the product obtained in step 1 which has already been dissolved in a mixture of distilled water $(20 \mathrm{~mL})$ with methanol $(85$ $\mathrm{mL}$ ) and stirred for $3 \mathrm{~h}$ at room temperature. The resultant precipitate was filtered off after $48 \mathrm{~h}$, washed with distilled water, ethanol, acetone, and ether and allowed to dry (yield $0.070 \mathrm{~g}$ ). The dried product (III) is a dark green-coloured crystalline compound. (UV-vis (DMF, $\lambda_{\max } / \mathrm{nm}$ ): $313 \mathrm{~nm}, 450 \mathrm{~nm}, 685 \mathrm{~nm}$. FTIR $\nu_{\max } / \mathrm{cm}^{-1}: 3400\left(\nu_{\mathrm{O}-\mathrm{H}}\right), 1605\left(\nu_{\mathrm{C}-\mathrm{O}}\right), 1550\left(\nu_{\mathrm{C}-\mathrm{O}}\right), 1200$ $\left(\nu_{\mathrm{COO}}\right)$. Elemental analysis: found: $\mathrm{C} 25.60, \mathrm{H} 1.39, \mathrm{~N} 6.34 \%$. $\mathrm{C}_{40} \mathrm{H}_{24} \mathrm{~N}_{8} \mathrm{FeO}_{24} \mathrm{Pt}_{4}$ requires $\mathrm{C} 26.14, \mathrm{H} \mathrm{1.31,} \mathrm{N} \mathrm{6.10 \% ).} \mathrm{Molar}$ mass of $\mathrm{C}_{40} \mathrm{H}_{24} \mathrm{~N}_{8} \mathrm{O}_{24} \mathrm{FePt}_{4}$ is $1836.8468 \mathrm{~g} \mathrm{~mol}^{-1}$. EDX atomic ratio: $\mathrm{Fe}(1.54 \pm 0.07)$ : $\mathrm{Pt}(7.81 \pm 0.17)$.

\subsection{Electrode preparation}

An edge plane pyrolytic graphite electrode (3 $\mathrm{mm}$ diameter) was polished to a mirror finish with alumina slurry (nano powder, Aldrich), and then cleaned by ultrasonic stirring in acetone and deionised water for $3 \mathrm{~min}$ respectively. $1 \mathrm{mg}$ of functionalised MWCNT was dispersed in $1 \mathrm{~mL}$ DMF with the aid of ultrasonic stirring. $15 \mu \mathrm{L}$ of the MWCNT solution were cast onto the EPPGE surface and allowed to dry at room temperature to prepare the EPPGE-MWCNT electrode. $15 \mu \mathrm{L}$ of the $\mathrm{PtFeOCPc}$ complex prepared in the same manner were cast onto the surface of the EPPGE-MWCNT to prepare the EPPGEMWCNT-PtFeOCPc electrode. Note that this procedure of modifying an electrode with the CNTs before depositing the electrocatalysts is well known. ${ }^{49,50}$

\subsection{Instruments and procedure}

The UV-Visible spectra were measured using a Cary 300 UVVisible Spectrophotometer, driven by the Varian software version 3.0 at a scan rate of $600 \mathrm{~nm} \mathrm{~min}^{-1}$. IR spectra were measured using a Perkin Elmer Spectrum RX 1 FTIR system attached with a MIRacle ATR with diamond/ZnSe crystal plate for transmission in the $400-4000 \mathrm{~cm}^{-1}$ range. Elemental analysis was carried out with a Carlo Erba NA 1500 Nitrogen Carbon Sulfur Analyser. Gas Chromatography (GC) was used to separate the gases, i.e. $\mathrm{N}$ (in the form of $\mathrm{N}_{2}$ ), $\mathrm{C}$ (in the form of $\mathrm{CO}_{2}$ ) and $\mathrm{S}$ (in the form of $\mathrm{SO}_{2}$ ), using a $\mathrm{He}$ carrier gas and a thermal conductivity detector, driven by PeakNet software (Dionex Corporation), with an external A/D interface (UI20 Universal Interface, Dionex). The sample was prepared for XRD analysis using a back loading preparation method. It was analyzed with a PANalytical X'Pert Pro powder diffractometer with X'Celerator detector and variable divergence and receiving slits with Fe filtered $\mathrm{Co}-\mathrm{K} \alpha$ radiation. The diffraction patterns were collected from $10^{\circ}$ to $90^{\circ}$. The phases were identified using the X'Pert Highscore plus software. Surface morphology of the functionalised MWCNT and PtFeOCPc complex was characterised using a JEOL JEM-2100 F/HT transmission electron microscope (TEM), operating at an accelerating voltage of 200 $\mathrm{keV}$, and Field emission scanning electron microscopy (FESEM) images were obtained from JEOL JSM 5800 LV (Japan) equipped with an energy dispersive X-ray spectroscopy (EDX). Digital processing of the TEM images was carried out using the UTHSCSA ImageTool ${ }^{\circledR}$ software version 3.0. Electrochemical measurement was performed with an Autolab PGSTAT 20 (Eco, Chemie, Utrecht, The Netherlands) equipped with GPES 4.9 software. The counter electrode was a platinum rod, and a $\mathrm{Ag} \mid \mathrm{AgCl}$ saturated $\mathrm{KCl}$ electrode was used as the reference electrode.

\section{Results and discussion}

\subsection{Spectroscopic and microscopic characterisation}

The PtFeOCPc (Scheme 1, complex III) was synthesised following the same strategy used for the cobalt derivative. ${ }^{48}$ As will be seen from the characterisation and electrocatalytic properties of the complex III, the introduction of the Pt at the periphery of the FeOCPc (complex I) led to changes in the physico-chemical properties of the complex I. For example, as also observed for the cobalt derivative by Dolotova and Kaliya, ${ }^{48}$ the replacement of the ionic bond, $\mathrm{Na}^{+}-\mathrm{O}^{-}$(complex II), by the $\mathrm{Pt}-\mathrm{O}$ covalent bond rendered the tetraplatinated iron phthalocyanine product III insoluble in water. Fig. 1 shows the comparative UV-visible spectra of FeOCPc and PtFeOCPc in DMF. The Q-bands of the two complexes occur almost at the same wavelength $(685 \mathrm{~nm})$, with a slight shift to the red region $(\sim 2 \mathrm{~nm})$ by the complex III. Second, there is a notable change in the spectral pattern of the B-band region (316-340 nm range); 


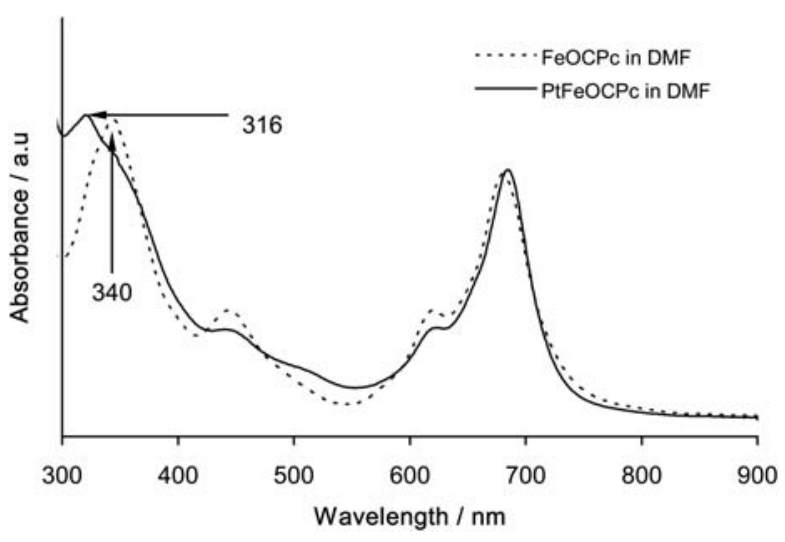

Fig. 1 Comparative UV-visible spectrum of FeOCPc and PtFeOCPc in DMF.

such change is characteristic of the introduction of the $\mathrm{Pt}$ at the periphery of the phthalocyanine ring and can conveniently serve for monitoring the formation of complex III. ${ }^{48}$ Third, notice the peak at $\sim 450 \mathrm{~nm}$, which is characteristic of the metal-to-ligand charge transfer band of the iron-containing phthalocyanine complexes. ${ }^{51-53}$

Elemental analysis data $(\mathrm{CHN})$ of the two $\mathrm{FePc}$ complexes closely agree with the expected values. The PtFeOCPc was further analysed with mass spectroscopy (Fig. 2). The peak at $\mathrm{m} / \mathrm{z}$ 1199.771 is attributed to the $\mathrm{C}_{36} \mathrm{H}_{18} \mathrm{~N}_{8} \mathrm{O}_{12} \mathrm{Pt}_{2} \mathrm{Fe}$ molecular ion, while that at $m / z 993.732$ may be related to the $\mathrm{C}_{36} \mathrm{H}_{6} \mathrm{~N}_{8} \mathrm{O}_{12} \mathrm{PtFe}$ fragment.

Fig. 3 presents the X-ray diffraction pattern of $\mathrm{FeOCPc}$ and $\mathrm{PtFeOCPc}$. The PtFeOCPc compound exhibited diffraction peaks different from its precursor, $\mathrm{FeOCPc}$, confirming the presence of Pt particles. ${ }^{54,55}$

The broad diffraction peak observed at $2 \theta$ of $31^{\circ}$ is due to $\mathrm{C}$ (003) which we associate with the phthalocyanine. This peak is more pronounced at the FeOCPc compound than its PtFeOCPc counterpart. The FeOCPc is amorphous, in agreement with the reported results where MPcs were found to be amorphous. ${ }^{56}$ The crystallinity of the PtFeOCPc is confirmed by the TEM image of the product (Fig. 4(a)). Fig. 4(b) presents the EDX profile of $\mathrm{PtFeOCPc}$; elemental analysis gave the expected atomic ratio of $1: 4(\mathrm{Fe}: \mathrm{Pt})$.

\subsection{Heterogeneous electron transfer behaviour}

Next, we explored the surface electrochemistry of these MPc complexes when immobilised on MWCNT-modified EPPGEs, first by examining their cyclic voltammetric evolutions in a solution of an outer-sphere redox probe, $\left[\mathrm{Fe}(\mathrm{CN})_{6}\right]^{3-} /\left[\mathrm{Fe}(\mathrm{CN})_{6}\right]^{4-}$. Fig. 5 presents the comparative cyclic voltammograms of the various electrodes studied in $0.1 \mathrm{M}\left[\mathrm{Fe}(\mathrm{CN})_{6}\right]^{3-/ 4-} 1.0 \mathrm{M} \mathrm{KCl}$ solution. When the same experiment was carried out in $1.0 \mathrm{M} \mathrm{KCl}$ alone, we did not observe any significant redox process compared to when the redox probe was present. This should perhaps not be surprising considering that it is usually very difficult to observe the redox couple $\left(\mathrm{M}^{2+} / \mathrm{M}^{3+}\right)$ of surface-confined transition MPc complexes in aqueous solution.

The heterogeneous electron transfer behaviour was determined by the analysis of the potential peak-to-peak separation $\left(\Delta E_{\mathrm{p}}\right)$ : the smaller the value the faster the electron transfer. The $\Delta E_{\mathrm{p}}$ increases as EPPGE-MWCNT-PtFeOCPc $(41 \mathrm{mV})<$ EPPGE-PtFeOCPc $(44 \mathrm{mV})<$ EPPGE-MWCNT $(56 \mathrm{mV})<$ EPPGE-MWCNTFeOCPc $(71 \mathrm{mV})<$ EPPGE-FeOCPc $(78 \mathrm{mV})<\operatorname{EPPGE}(90 \mathrm{mV})$,

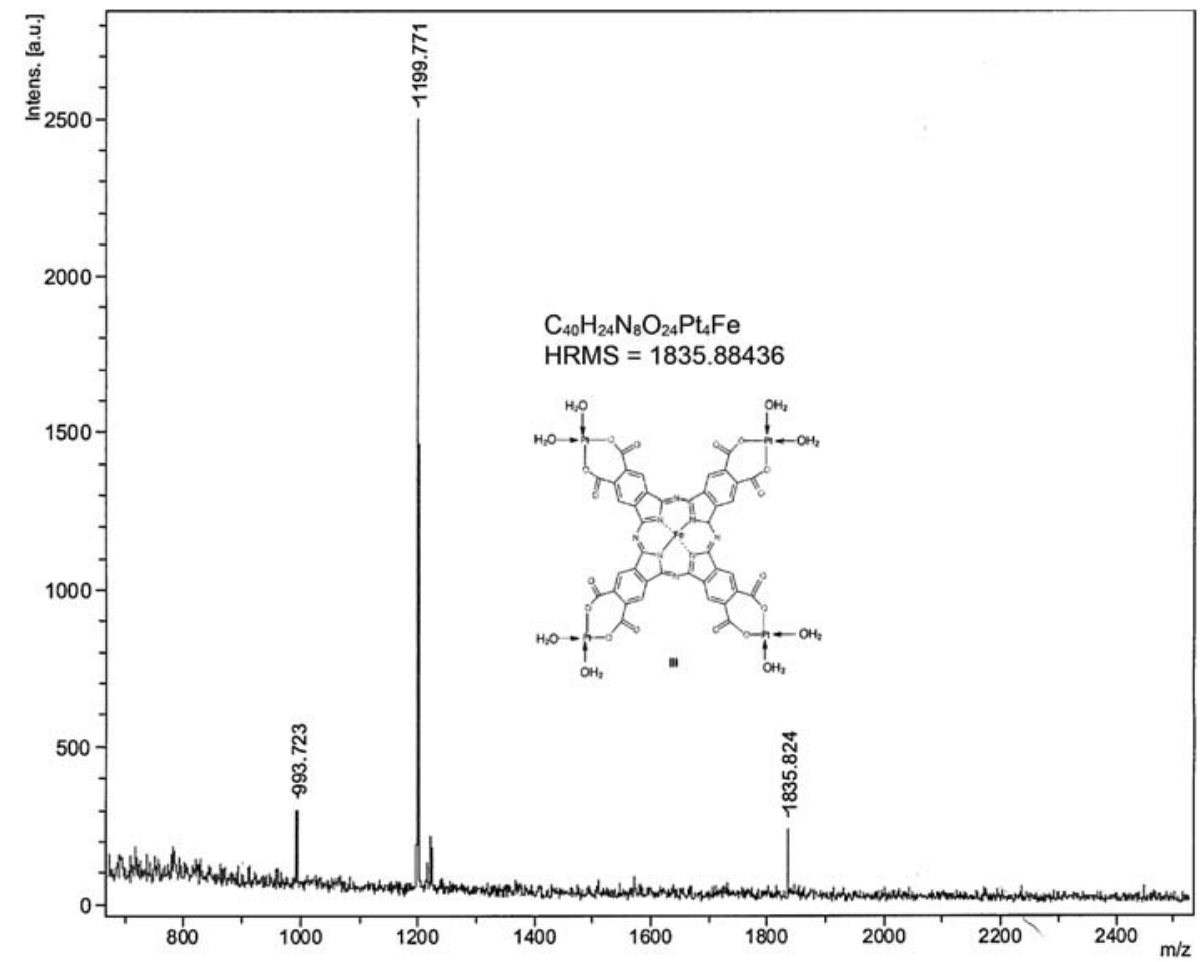

Fig. 2 High resolution mass spectra of iron(II) tetrakis(diaquaplatinum)octacarboxyphthalocyanine $\left(\mathrm{C}_{40} \mathrm{H}_{24} \mathrm{~N}_{8} \mathrm{FeO}_{24} \mathrm{Pt}_{4}\right)$. 


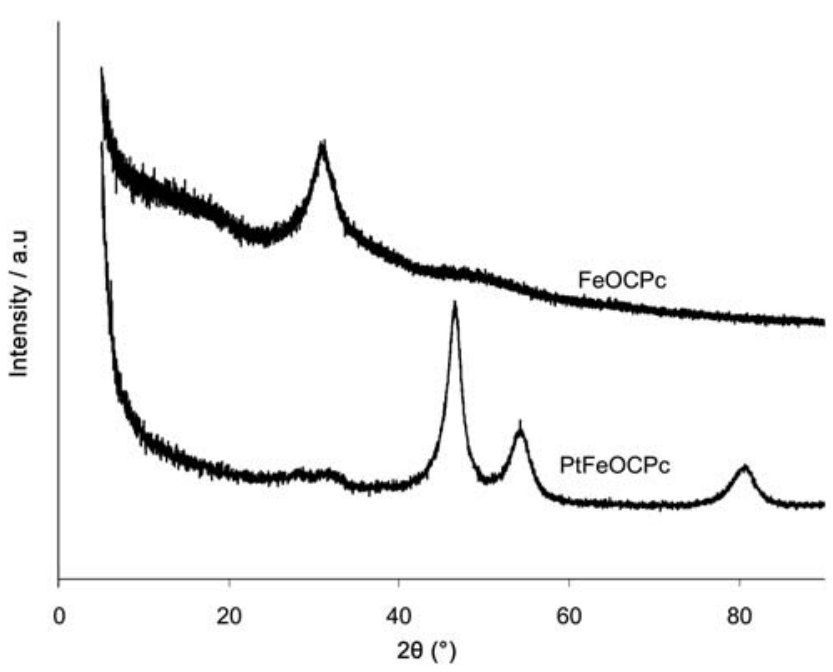

Fig. 3 Comparative XRD pattern of FeOCPc and PtFeOCPc.
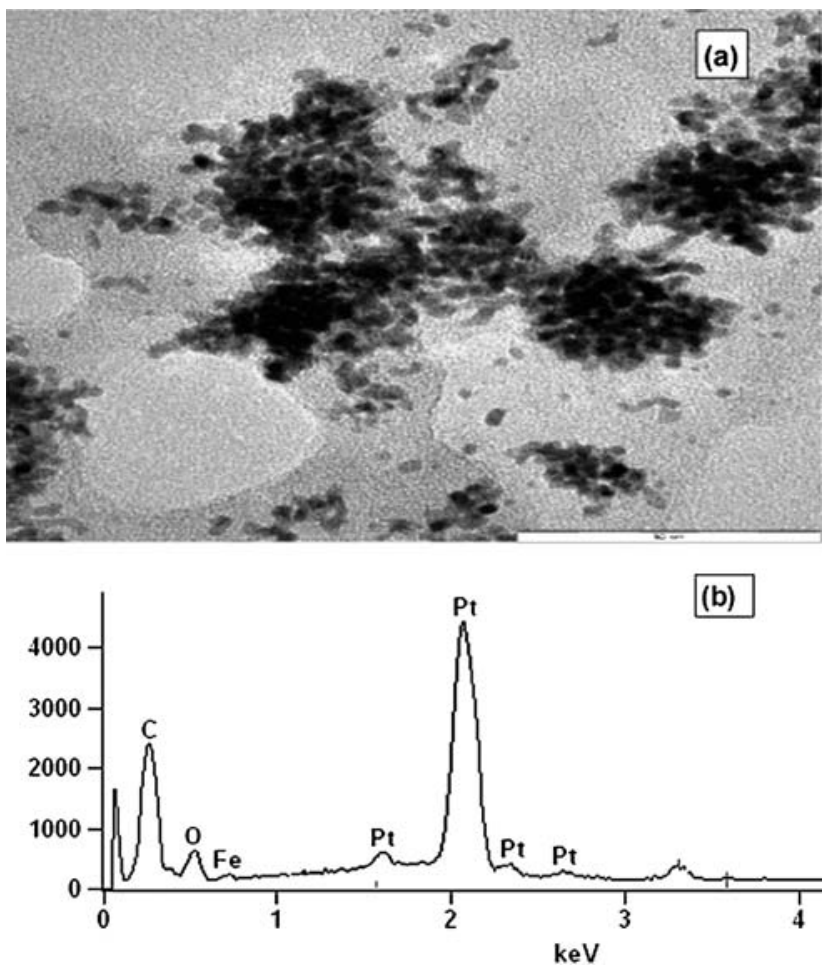

Fig. 4 Typical TEM image of MWCNT-COOH/PtFeOCPc (a) and EDX spectra of PtFeOCPc (b).

indicating that EPPGE-MWCNT-PtFeOCPc enhances faster electron transport compared to other electrodes in the conditions employed. It is seen from the CV that the MWCNT-based electrodes exhibited higher current (Faradaic) response in the $0.2-0.35 \mathrm{~V}$ region as well as higher capacitive (non-Faradaic) response in the -0.05 to $+0.1 \mathrm{~V}$ region. This observation may be related to a change in diffusion regime (i.e., semi-infinite linear diffusion and/or thin layer diffusion processes arising from the redox process of electroactive species/electrolytes $\left(\left[\mathrm{Fe}(\mathrm{CN})_{6}\right]^{4-}\right.$ / $\left.\left[\mathrm{Fe}(\mathrm{CN})_{6}\right]^{3-}\right)$ trapped within the porous structure or in pockets in between the high surface area nanotubes) as described by

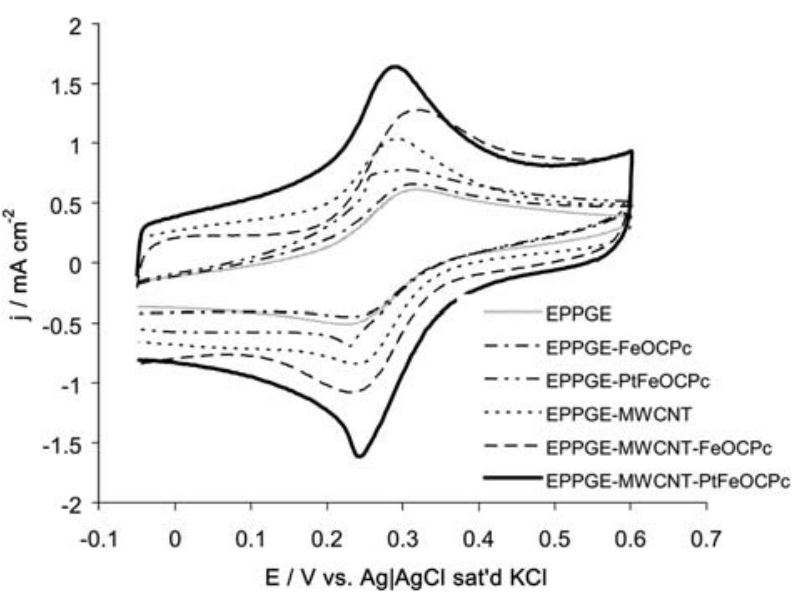

Fig. 5 Comparative cyclic voltammograms of the various electrodes in $0.1 \mathrm{M}\left[\mathrm{Fe}(\mathrm{CN})_{6}\right]^{3-14-} 1.0 \mathrm{M} \mathrm{KCl}$ solution.

Compton group. ${ }^{57}$ The porous structure of the complex may be seen from the comparative SEM images of the acid-functionalised MWCNT (a) and MWCNT/PtFeOCPc (b) (Fig. 6).

Electrochemical impedance spectroscopy (EIS) is considered a powerful tool in probing the processes that occur at the electrodelelectrolyte interface, and is often used as a complementary technique to cyclic voltammetry. ${ }^{58-62}$ Fig. 7(a) presents the Nyquist plots for the various electrodes studied in $\left[\mathrm{Fe}(\mathrm{CN})_{6}\right]^{4-/ 3-}$ solution. The impedance spectra of the electrodes were satisfactorily fitted with the modified Randles equivalent electrical circuits (Fig. 7(d)). The bare EPPGE electrode was fitted with circuit (i) while the other electrodes were fitted with circuit (ii). The fitting parameters involve the electrolyte resistance $\left(R_{\mathrm{S}}\right)$, electron-transfer resistance $\left(R_{\mathrm{ct}}\right)$, constant phase element (CPE), double layer capacitance $\left(C_{\mathrm{dl}}\right)$ and Warburg-type impedance $\left(Z_{\mathrm{w}}\right)$ which is associated with the diffusion of the ions of the redox probe.

The electron transfer rate constants $\left(k^{\circ}\right)$ may be obtained from the $R_{\mathrm{ct}}$ values using the derived eqn (6)-(8). ${ }^{63,64}$

$$
\begin{gathered}
R_{\mathrm{ct}}=\frac{R T}{n F i_{\mathrm{o}}} \\
i_{\mathrm{o}}=n F A k^{\circ} C_{\mathrm{O}}^{\infty} C_{\mathrm{R}}^{\infty}
\end{gathered}
$$

Combining eqn (6) and (7), taking the activity coefficients $(\infty)$ equal to unity, and assuming the bulk concentrations of the
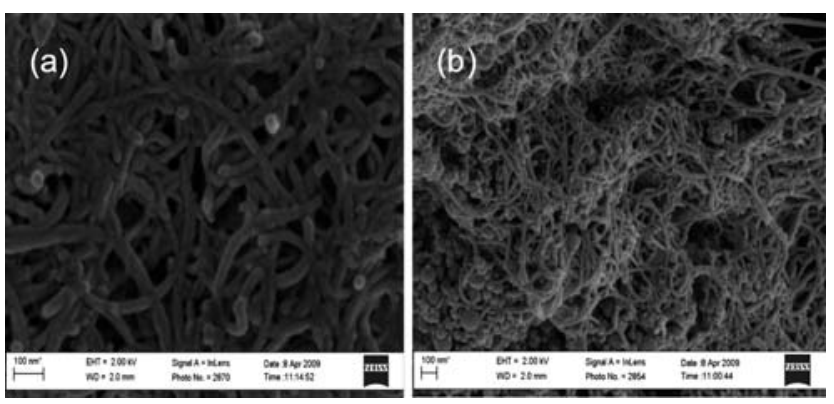

Fig. 6 Typical SEM images of MWCNT-COOH (a) and MWCNT$\mathrm{COOH} / \mathrm{PtFeOCPc}(\mathrm{b})$. 

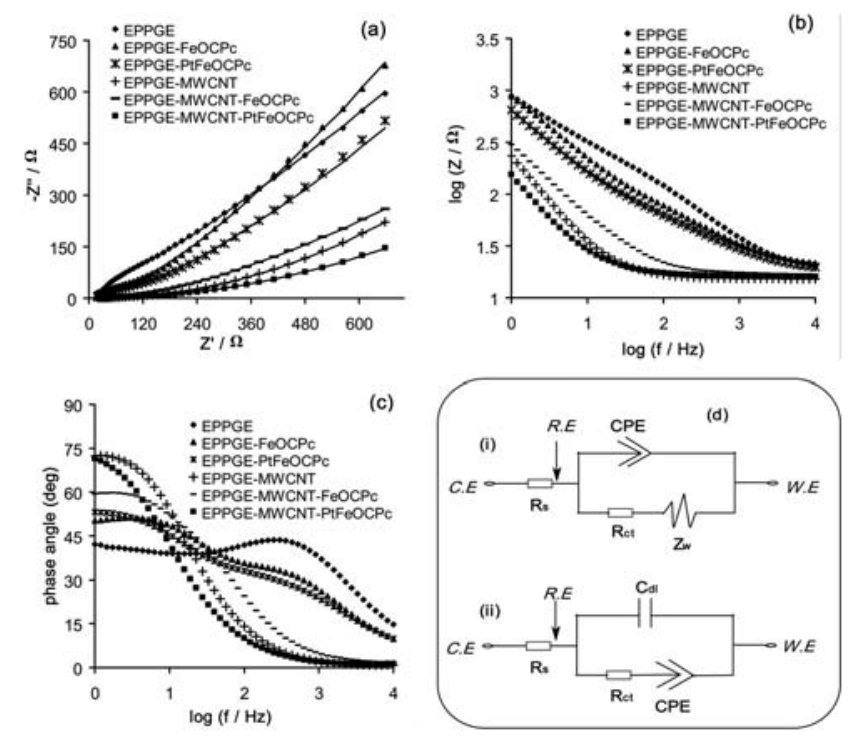

Fig. 7 Comparative Nyquist plots (a), and Bode plots: (b) $\log$ of impedance magnitude $v s . \log f$, and (c) phase angle $v s . \log f$ of the various electrodes in $0.1 \mathrm{M}\left[\mathrm{Fe}(\mathrm{CN})_{6}\right]^{3-14-} 1.0 \mathrm{M} \mathrm{KCl}$ solution. (---) Simulated plots and $(\boldsymbol{\Lambda})$ measured plots. Equivalent electrical circuit used for fitting the measured data $(\mathrm{d})$.

oxidised and reduced species to be equal $\left(C_{\mathrm{O}}^{\infty}=C_{\mathrm{R}}^{\infty}=C\right)$ such that the equilibrium potential $\left(E_{1 / 2}\right)$ equals the formal redox potential $\left(E_{\mathrm{O} / \mathrm{R}}^{\phi}\right)$, then the $k^{\circ}$ becomes

$$
k^{\mathrm{o}}=\frac{R T}{n^{2} F^{2} A R_{\mathrm{ct}} C}
$$

where $n$ is the number of electron transferred $(=1), A$ is the geometric area of the electrode, $C$ is the concentration of the redox probe (in mol cm${ }^{-3}$, the concentration of $\left[\mathrm{Fe}(\mathrm{CN})_{6}\right]^{3-}$ and $\left[\mathrm{Fe}(\mathrm{CN})_{6}\right]^{4-}$ are equal), $R$ is the ideal gas constant, $T$ is the absolute temperature and $F$ is the Faraday constant. The calculated values are shown in Table 1 . The $k^{\circ}$ values decreases as: EPPGE-MWCNT-PtFeOCPc $\left(776 \times 10^{-3} \mathrm{~cm} \mathrm{~s}^{-1}\right)>$ EPPGE-MWCNT $\left(681 \times 10^{-3} \mathrm{~cm} \mathrm{~s}^{-1}\right)>$ EPPGE-PtFeOCPc $\left(176 \times 10^{-3} \mathrm{~cm} \mathrm{~s}^{-1}\right)>$ EPPGE-MWCNT-FeOCPc $\left(159 \times 10^{-3}\right.$ $\left.\mathrm{cm} \mathrm{s}^{-1}\right)>$ EPPGE-FeOCPc $\left(151 \times 10^{-3} \mathrm{~cm} \mathrm{~s}^{-1}\right)>\operatorname{EPPGE}(20 \times$ $10^{-3} \mathrm{~cm} \mathrm{~s}^{-1}$ ) implying that the electron transfer processes between the redox probe and the underlying EPPGE surface is faster at the EPPGE-MWCNT-PtFeOCPc compared to the other electrodes, corroborating the $\mathrm{CV}$ data. Note that $\mathrm{CPE}$ arises from factors such as: (i) the nature of the electrode (e.g., roughness and polycrystallinity), (ii) distribution of the relaxation times due to heterogeneities existing at the electrode/electrolyte interface, (iii) porosity and (iv) dynamic disorder associated with diffusion. From the Bode plots, Fig. 7(b) and (c), the slopes of the $\log Z v s$. $\log f$ plot at the mid-frequency region are less than the ideal -1.0 for pure capacitive behaviour, which is indicative of the pseudocapacitive behaviour. Also, the EPPGE-MWCNT-PtFeOCPc shows the least impedance value compared to other electrodes. The data from the other Bode plot (i.e., phase angle $(\phi) v s . \log f$ ) confirm the absence of ideal capacitive behaviour as the observed phase angles are less than the $90^{\circ}$ expected of an ideal capacitive behaviour. It is only the bare EPPGE that shows a maximum at $\sim 44^{\circ}$, close to the ideal Warburg value of $45^{\circ}$. This relaxation process is shifted to different phase angles upon modification, indicating that the $\left[\mathrm{Fe}(\mathrm{CN})_{6}\right]^{3-14-}$ redox process now takes place at the surface of the modifying films than directly on the bare EPPGE surface.

\subsection{Electrocatalytic oxidation of formic acid}

3.3.1. Comparative cyclic voltammetric response. The electrocatalytic properties of EPPGE-MWCNT-PtFeOCPc for formic acid oxidation were studied in $0.5 \mathrm{M} \mathrm{HCOOH}+0.5 \mathrm{M}$ $\mathrm{H}_{2} \mathrm{SO}_{4}$ aqueous solution by cyclic voltammetry. Fig. 8 presents the cyclic voltammograms of the various electrodes.

The classical formic acid electro-oxidation peaks were observed only with the EPPGE-PtFeOCPc and EPPGEMWCNT-PtFeOCPc electrodes, implying that the electrocatalytic activity for the oxidation of formic acid takes place in the presence of the platinum containing catalysts. Two distinct oxidation peaks can be observed at $\sim 0.20$ and $\sim 0.70 \mathrm{~V}$ for the forward scan and a backward oxidation peak at $\sim 0.20 \mathrm{~V}$. The first peak at $\sim 0.20 \mathrm{~V}$ is attributed to the direct oxidation of formic acid to $\mathrm{CO}_{2}$ (i.e., direct pathway) ${ }^{65,66}$ This peak is usually used to evaluate the electrocatalytic activity of the catalyst. The peak at $\sim 0.70 \mathrm{~V}$ is attributed to the rapid oxidation of adsorbed $\mathrm{CO}$ on the surface of the catalyst and formic acid by sites that have been poisoned by the adsorption of $\mathrm{CO}$ (poisoning of surface active sites) and the subsequent release of these sites by CO stripping. ${ }^{45,67,68}$ The reverse peak at $\sim 0.20 \mathrm{~V}$ is related to the direct oxidation of formic acid to $\mathrm{CO}_{2}$ after the adsorbed $\mathrm{CO}$ has been removed at increased electrode potential with the subsequent recovery of the surface active sites. Notice that unlike the EPPGE-PtFeOCPc, the EPPGE-MWCNT-PtFeOCPc showed

Table 1 Impedance parameters obtained for the various electrodes studied in $0.1 \mathrm{M}\left[\mathrm{Fe}(\mathrm{CN})_{6}\right]^{3-/ 4-} 1.0 \mathrm{M} \mathrm{KCl}$ solution using the electrical equivalent circuit in Fig. 7

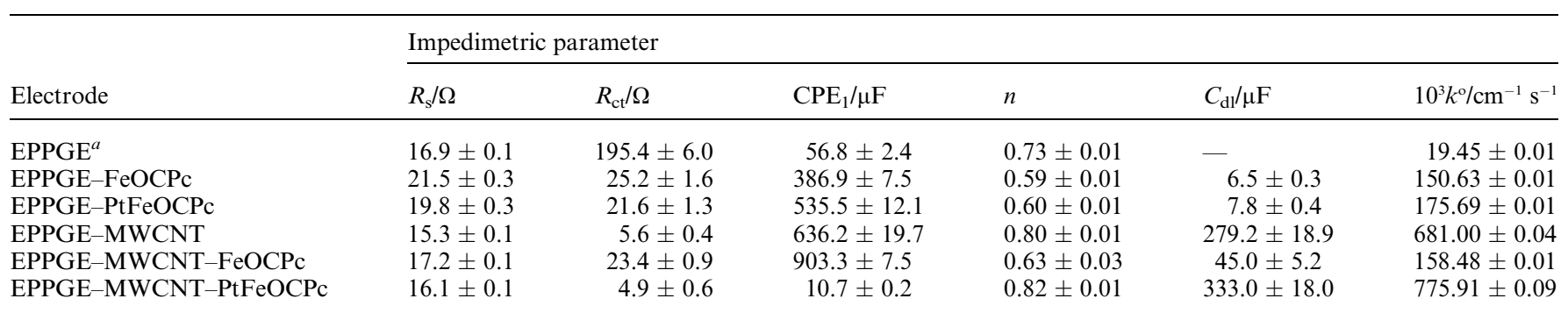

${ }^{a} Z_{\mathrm{w}}$ of EPPGE is $(433 \pm 3.81) \times 10^{-6} \Omega$. 

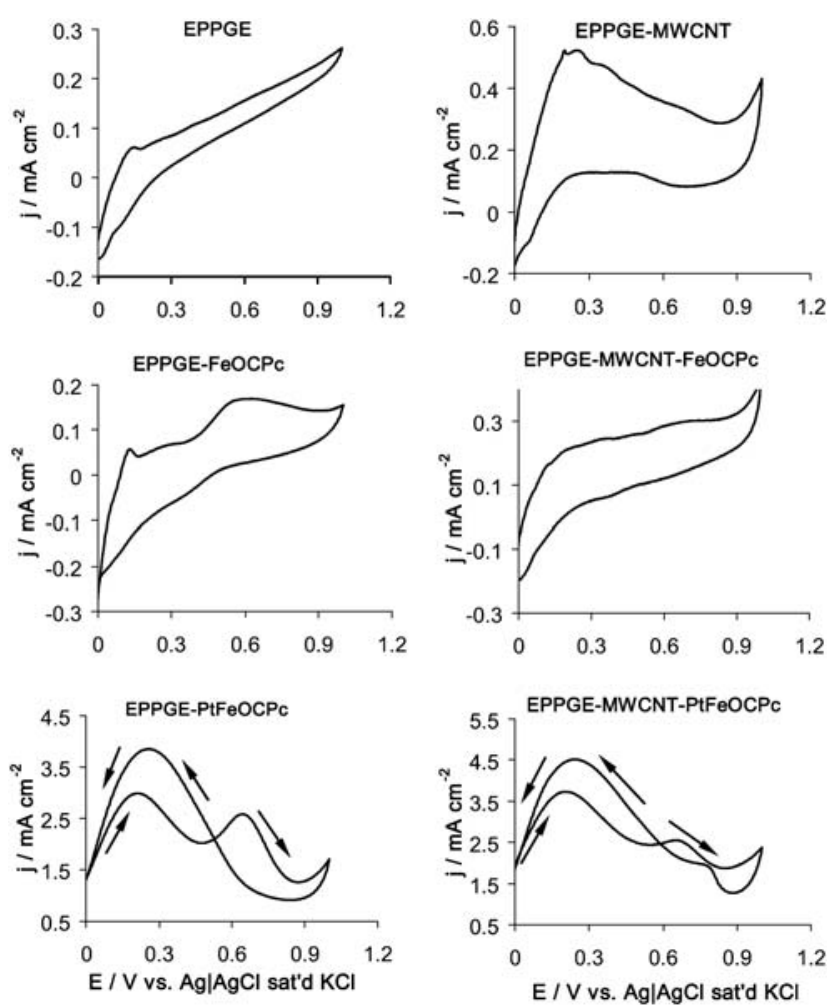

Fig. 8 Cyclic voltammograms of the various electrodes in $0.5 \mathrm{M} \mathrm{H}_{2} \mathrm{SO}_{4}$ containing $0.5 \mathrm{M} \mathrm{HCOOH}$ solution.

a small reverse peak at around $0.8 \mathrm{~V}$. A similar peak was observed recently by Maxakato et al. ${ }^{69}$ who attributed it to further oxidation of the $\mathrm{CO}$ or FA.

It can be seen in Fig. 8 that the onset for the electro-oxidation of formic acid in the EPPGE-PtFeOCPc and EPPGEMWCNT-PtFeOCPc electrodes is almost immediate. The current densities of the forward oxidation peaks are $\sim 2.96$ and $\sim 2.55 \mathrm{~mA} \mathrm{~cm}^{-2}$ for the EPPGE-PtFeOCPc electrode and $\sim 3.71$ and $\sim 2.51 \mathrm{~mA} \mathrm{~cm}^{-2}$ for the EPPGE-MWCNT-PtFeOCPc electrode. According to Zhou et al., ${ }^{45}$ the ratio of the current densities under the first and second forward oxidation is used to determine the pathway for the electro-oxidation of formic acid. A low ratio indicates that formic acid oxidation proceeds via the "CO pathway" and a high ratio implies that formic acid oxidation proceeds via the direct pathway. The ratios of the current densities calculated for EPPGE-PtFeOCPc and EPPGEMWCNT-PtFeOCPc are $\sim 1.2$ and $\sim 1.5$ respectively. These mean that both electrodes favour the direct pathway. According to Chen et al. ${ }^{68}$ the ratio of the current densities under the first forward oxidation peak and the reverse oxidation peak essentially reflects the fraction of catalyst surface that is not poisoned by $\mathrm{CO}$ adsorption. A low ratio implies a low tolerance to $\mathrm{CO}$ poisoning, while a high ratio implies a high tolerance to $\mathrm{CO}$ poisoning. The ratios of the current densities calculated for EPPGE-PtFeOCPc and EPPGE-MWCNT-PtFeOCPc are approximately 1 , meaning that both electrodes have high tolerance to $\mathrm{CO}$ poisoning. For the reverse oxidation, an oxidation peak at almost the same potential is observed, with a current density of $\sim 4 \mathrm{~mA} \mathrm{~cm}^{-2}$ for the EPPGE-PtFeOCPc electrode and $\sim 5 \mathrm{~mA} \mathrm{~cm}{ }^{-2}$ for the EPPGE-MWCNT-PtFeOCPc electrode.
The difference in current density between the first oxidation peak and the reverse oxidation peak for the EPPGE-PtFeOCPc electrode is attributed to the effect of formation of $\mathrm{CO}$ poisoning intermediate(s) and their adsorption on the catalyst surface. ${ }^{56}$ However, this difference is minimal in the EPPGE-MWCNT$\mathrm{PtFeOCPc}$ electrode, implying that the activity of the catalyst significantly improved when supported on MWCNT. MWCNT is known to act as an efficient supporting material for the effective dispersion of the catalyst for electrocatalytic applications. ${ }^{69}$ The forward peak at the $0.2 \mathrm{~V}$ is due to the direct oxidation of the FA. ${ }^{45,66}$ Note that the forward peak current at $0.2 \mathrm{~V}$ is higher than that at $0.7 \mathrm{~V}$, this means that there is an absence or low impact of surface-bound $\mathrm{CO}$ on the catalyst. Such phenomenon is rarely observed at several electrodes, an example is in the work of Selvaraj et ll $^{70}$ The direct oxidation process observed here may be related to the promotional effect of the phthalocyanine as also postulated by Zhou et al. ${ }^{45}$ for FeTSPc immobilised onto a Pt disc electrode. We do not fully understand the reason for this enhanced reaction, however, other workers ${ }^{71,72}$ have attributed such observation to the enhanced dehydration reaction in the $\mathrm{CO}$ pathway that generates the $\mathrm{CO}_{\mathrm{ad}}$ intermediates. Also, the electronic effect generated by the availability of electrons in the FeOCPc macrocycle could favour the electro-oxidation of formic acid by changing the electron distribution on the platinum surface, hence affecting the reaction pathway. ${ }^{73}$ It should be noted here that Pt nanoparticles alone electrodeposited onto MWCNT (MWCNT-Pt) showed poorer current response towards formic acid compared to the MWCNT-PtFeOCPc. This result is in agreement with the previous report of our group. ${ }^{69}$

3.3.2. Chronoamperometry experiment. Chronoamperometry experiments were performed to provide further insights into the achievable current densities by the electrodes. Fig. 9 presents the current-time curve of the electrodes studied, showing that the current density first drops to $\sim 0.21 \mathrm{~mA} \mathrm{~cm}^{-2}$ and then to a steady value at $\sim 0.13 \mathrm{~mA} \mathrm{~cm}{ }^{-2}$ after about 2 min for the EPPGE$\mathrm{PtFeOCPc}$ electrode, while for the EPPGE-MWCNT-PtFeOCPc

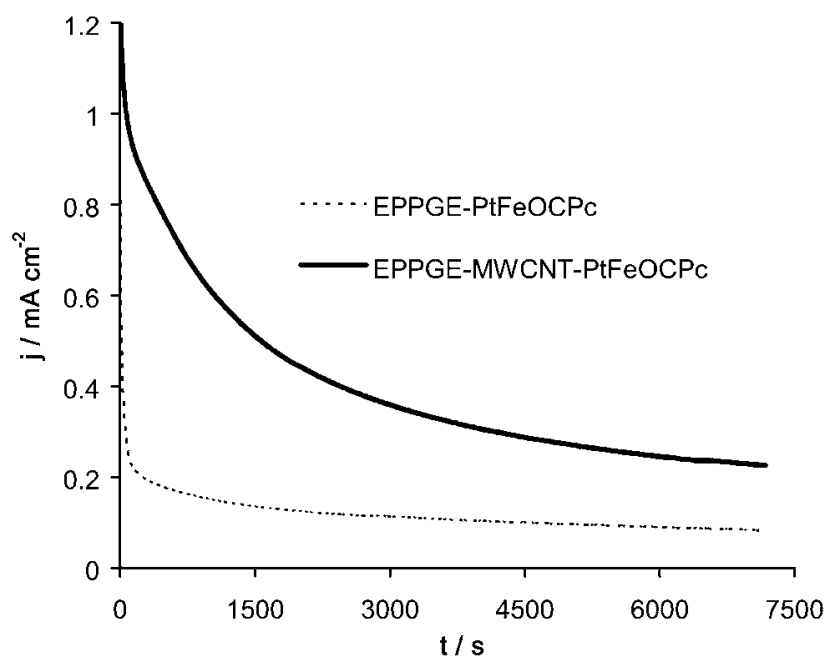

Fig. 9 Chronoamperometric curves of EPPGE-PtFeOCPc and EPPGE-MWCNT-PtFeOCPc in $0.5 \mathrm{M} \mathrm{H}_{2} \mathrm{SO}_{4}$ containing $0.5 \mathrm{M}$ $\mathrm{HCOOH}$ solution. 
electrode, the current dropped initially to $\sim 0.47 \mathrm{~mA} \mathrm{~cm}^{-2}$ and then to a steady value at $\sim 0.27 \mathrm{~mA} \mathrm{~cm}^{-2}$ after about $5 \mathrm{~min}$. The stable current for the EPPGE-MWCNT-PtFeOCPc electrode is much higher than EPPGE-PtFeOCPc.

The stability of the EPPGE-MWCNT-PtFeOCPc at a high current signifies better activity towards formic acid oxidation. This confirms our results from cyclic voltammetry.

An insight into the electrocatalytic rate constants $\left(k_{\mathrm{cat}}\right)$ at the two electrodes was obtained by employing the conventional equation below: ${ }^{63}$

$$
\frac{j_{\mathrm{cat}}}{j_{\mathrm{buff}}}=\pi^{1 / 2}\left(k_{\mathrm{cat}} C_{\mathrm{o}} t\right)^{1 / 2}
$$

where $j_{\text {cat }}$ and $j_{\text {buff }}$ are the current densities in the presence and absence of formic acid, $C$ is the bulk concentration and $t$ is the time. A value of $41.09 \mathrm{~cm}^{3} \mathrm{~mol}^{-1} \mathrm{~s}^{-1}$ was obtained for the EPPGEMWCNT-PtFeOCPc and $10.95 \mathrm{~cm}^{3} \mathrm{~mol}^{-1} \mathrm{~s}^{-1}$ for the EPPGEPtFeOCPc, further confirming the higher electrocatalytic performance of the EPPGE-MWCNT-PtFeOCPc. There is no available literature to adequately compare the $k_{\text {cat }}$ values determined in this work. However, the values are smaller than the $2.45 \times 10^{-1} \mathrm{~L} \mathrm{~mol}^{-1} \mathrm{~s}^{-1}$ (i.e., $245 \mathrm{~cm}^{3} \mathrm{~mol}^{-1} \mathrm{~s}^{-1}$ ) reported by Blake and Hinshelwood ${ }^{74}$ for gaseous formic acid. Considering the higher performance of the EPPGE-MWCNT-PtFeOCPc, all subsequent studies (unless otherwise stated) was devoted to this electrode.

3.3.3. Concentration studies: Tafel analysis. The effect of formic acid concentration on the electrocatalysis was studied at concentrations ranging from 0.10 to $1.20 \mathrm{M}$ formic acid in 0.5 $\mathrm{M} \mathrm{H}_{2} \mathrm{SO}_{4}$ solution at EPPGE-MWCNT-PtFeOCPc. Fig. 10(a) shows that the current density increases as concentration increases and starts to decrease at $0.90 \mathrm{M}$, meaning that mass transfer resistances and build up of interfacial $\mathrm{CO}_{2}$ formed during the electro-oxidation process or the combination of both might be responsible for this deviation at high concentration. ${ }^{75}$ Simply stated, at $>0.75 \mathrm{M}$ the catalyst becomes easily saturated, meaning that optimum catalysis occurs at $0.75 \mathrm{M}$ formic acid.

Next we investigated the electrocatalytic properties by analyzing the Tafel behaviour, using the conventional relationships for oxidation processes, eqn (10) and (11): ${ }^{63}$

$$
\begin{gathered}
\eta=a+b \log j \\
b=\frac{2.303 R T}{(1-\alpha) n F}
\end{gathered}
$$

where $\eta$ is the overpotential (difference between the applied potential and the open circuit potential), $j$ is the current density, $b$ is the Tafel slope, $a$ is the Tafel constant relating to the exchange current density, $\alpha$ is the transfer coefficient, $n$ is the number of electrons involved in the rate determining step, while other symbols retain their usual meaning. From the plots of $\eta v s . \log j$ (Fig. 10(b)), the Tafel slopes were essentially the same (275-290 $\mathrm{mV} \mathrm{dec}{ }^{-1}$ range) at all concentrations, indicating that the same reaction mechanism is probably operating at all the concentrations of the formic acid studied. The high value of the Tafel slope obtained is characteristic of porous electrode with high internal surface area leading to high electrocatalytic activities. ${ }^{76}$
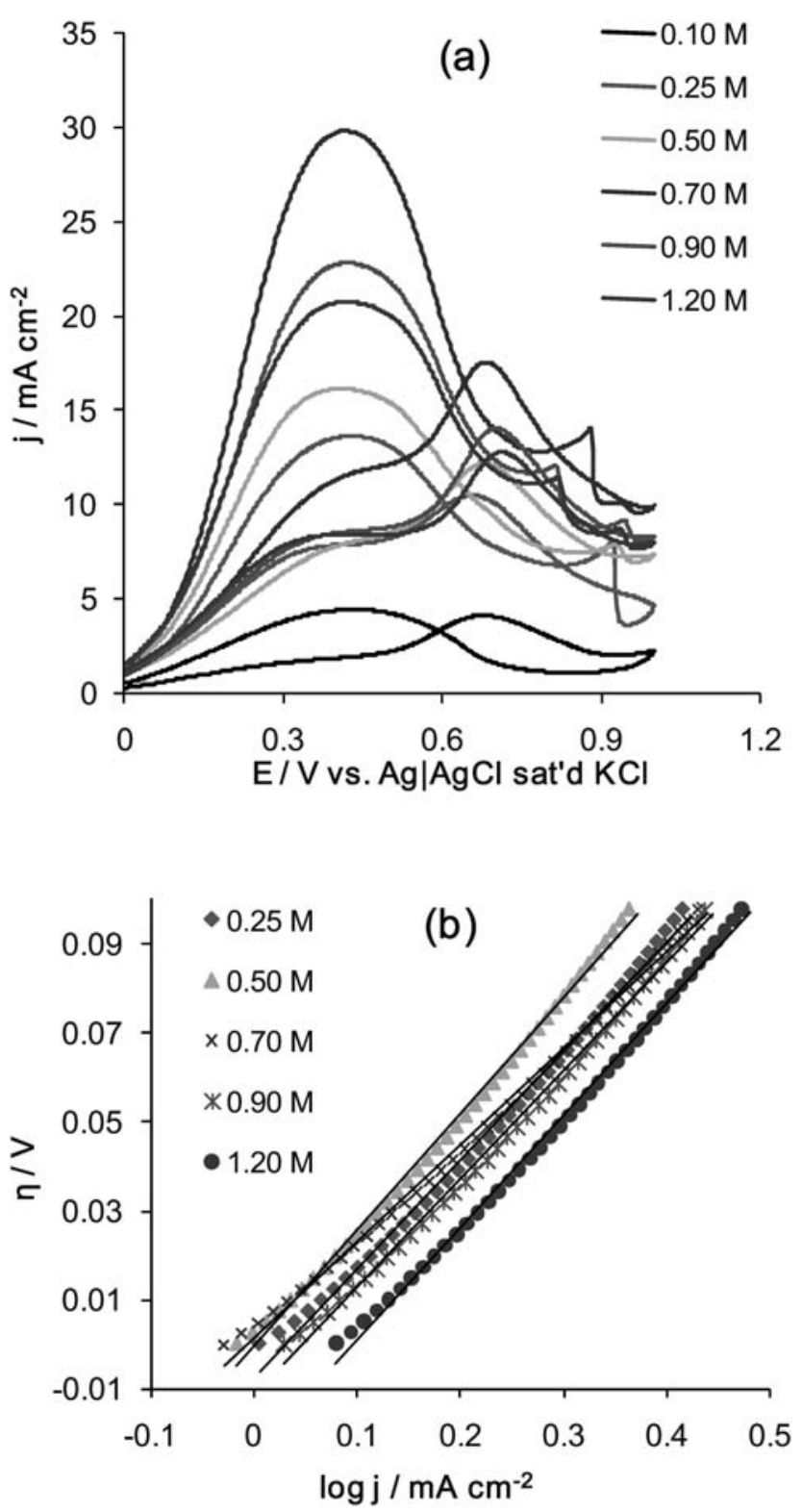

Fig. 10 Cyclic voltammetric evolutions following changes in the concentration of formic acid (a) and Tafel plots of $\eta$ against $\log j$ at different concentrations of formic acid (b).

3.3.4. Electrochemical impedance spectroscopy experiments. EIS was employed to further interrogate the electrocatalytic activity of the EPPGE-MWCNT-PtFeOCPc towards formic acid oxidation. Fig. 11(a) presents the Nyquist plots while Fig. 11(b) and (c) were the Bode plots obtained at different potentials measured in $0.5 \mathrm{M} \mathrm{HCOOH}+0.5 \mathrm{M} \mathrm{H}_{2} \mathrm{SO}_{4}$ solution. The Frumkin-Melik-Gaikazyan (FMG) ${ }^{77}$ equivalent electrical circuit (Fig. 11(d)) was used to fit the EIS data. In the circuit the symbol $C_{\text {ad }}$ represents the adsorption capacitance arising from the oxidation of carbonaceous species on the electrode surface, while other symbols retain their usual meaning.

It can be seen from the figure that all measured spectra are in the same quadrant (i.e., the conventional positive Faradaic impedance) at all peak potentials measured, which is indicative of the absence of adsorbed intermediates. This is interesting 

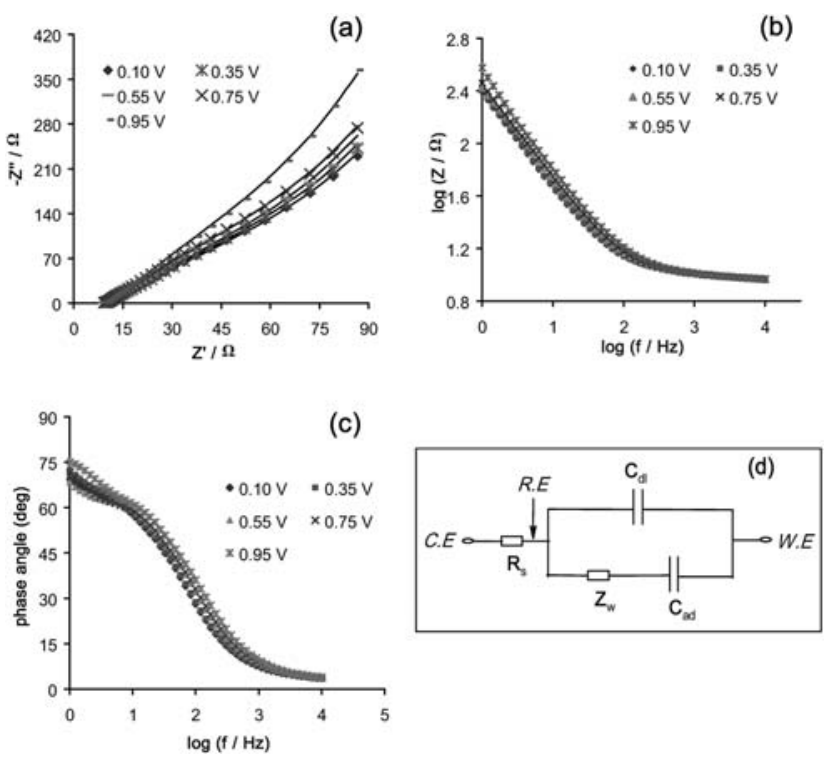

Fig. 11 Typical Nyquist (a), Bode (b and c) plots and equivalent circuit (d) used to fit the spectra obtained at different potentials $(0.10,0.35,0.55$, 0.75 and $0.95 \mathrm{~V}$ ) for EPPGE-MWCNT-PtFeOCPc in $0.5 \mathrm{M} \mathrm{H}_{2} \mathrm{SO}_{4}$ containing $0.5 \mathrm{M} \mathrm{HCOOH}$.

Table 2 Impedance data obtained for EPPGE-MWCNT-PtFeOCPc electrode studied in $0.5 \mathrm{M} \mathrm{H}_{2} \mathrm{SO}_{4}$ containing $0.5 \mathrm{M} \mathrm{HCOOH}$ at different potentials using the electrical equivalent circuit in Fig. 11

\begin{tabular}{|c|c|c|c|c|}
\hline \multirow{2}{*}{$\begin{array}{l}\text { Bias } \\
\text { potential/V vs. } \\
\mathrm{Ag} / \mathrm{AgCl} \\
\text { sat'd } \mathrm{KCl}\end{array}$} & \multicolumn{4}{|c|}{ Impedimetric parameter } \\
\hline & $R_{\mathrm{s}} / \Omega$ & $C_{\mathrm{dl}} / \mu \mathrm{F}$ & $C_{\mathrm{ad}} / \mathrm{mF}$ & $10^{3} Z_{\mathrm{w}} / \Omega$ \\
\hline 10 & $9.82 \pm 0.10$ & $133.70 \pm 7.42$ & $0.88 \pm 0.04$ & $2.72 \pm 0.14$ \\
\hline 0.35 & $9.75 \pm 0.10$ & $121.40 \pm 6.93$ & $0.79 \pm$ & $2.89 \pm 0.14$ \\
\hline 0.55 & $9.80 \pm 0.10$ & $117.70 \pm 5.49$ & $0.92 \pm 0.08$ & $2.15 \pm 0.09$ \\
\hline 0.75 & $9.73 \pm 0.08$ & $102.00 \pm 4.63$ & $0.78 \pm 0.03$ & $2.26 \pm 0.09$ \\
\hline 0.95 & $9.63 \pm 0.07$ & $80.10 \pm 3.57$ & $0.51 \pm 0.01$ & $2.37 \pm 0.09$ \\
\hline
\end{tabular}

considering that other workers such as Chen et al. ${ }^{68,78}$ Seland et al. ${ }^{65}$ and Maxakato et al. ${ }^{69}$ have observed negative Faradaic impedance and attributed such phenomenon to adsorbed intermediates resulting from the formation of chemisorbed hydroxyl species that compete for surface adsorption sites against the CO. The implication of the data in Table 2 resulting from the modelling of this electrode should be emphasised. First, since the FMG electrical equivalent circuit used in fitting our measured data is popularly used for studying adsorbed organic molecules, ${ }^{79}$ the presence of adsorbed species cannot be completely ruled out in this work. Second, the values of the $R_{\mathrm{s}}$ and $Z_{\mathrm{w}}$ are approximately the same. Ideally, $R_{\mathrm{s}}$ and $Z_{\mathrm{w}}$ values should not be affected by modification of the electrode surface. ${ }^{80}$ Third, considering that electron transfer rate constant is inversely proportional to the $C_{\text {ad }}{ }^{62,81}$ it suggests that reaction kinetics tends to be faster at higher potentials $(\geq 0.90 \mathrm{~V})$. Thus, the low adsorption capacitance at more positive potential suggests some oxidative removal of carbonaceous species present on the electrode surface. The corresponding Bode plots clearly show the phase angles of the electrocatalytic processes as $65^{\circ}$ and $\geq 70^{\circ}$, confirming the presence of $\mathrm{CPE}$ and the pseudo-capacitive nature of the electrode since the angle is less than $90^{\circ}$ for an ideal capacitive behaviour. The slopes from the plot of $\log Z v s . \log f$ were approximately -0.68 and -0.05 at mid- and high-frequency regions, respectively, indicative of pseudo-capacitive and resistive behaviour at these frequency regions.

3.3.5. Tolerance to carbon monoxide poisoning. Adsorption of CO-like species on the surface of the electrocatalyst is used to evaluate the extent to which an electrocatalyst can tolerate poisoning in a fuel cell system such as direct formic acid fuel cell (DFAFC). ${ }^{82,83}$ Thus, we conducted a preliminary experiment to determine the tolerance of the proposed electrocatalyst for formic acid oxidation towards CO. Fig. 12 shows the comparative CVs of EPPGE-PtFeOCPc (Fig. 12(a)) and EPPGE-MWCNTPtFeOCPc (Fig. 12(b)) in $0.5 \mathrm{M} \mathrm{H}_{2} \mathrm{SO}_{4}$ solution (I), $0.5 \mathrm{M} \mathrm{H}_{2} \mathrm{SO}_{4}$ saturated with $\mathrm{CO}$ (II), and $0.5 \mathrm{M}$ FA containing $0.5 \mathrm{M} \mathrm{H}_{2} \mathrm{SO}_{4}$ saturated with $\mathrm{CO}$ (III). The MWCNT-PtFeOCPc also shows the unique reverse peak at $\sim 0.8 \mathrm{~V}$ as in Fig. 8. The peak potential for $\mathrm{CO}$ oxidation at the EPPGE-PtFeOCPc is slightly $(\sim 40 \mathrm{mV})$ more positive than at the EPPGE-MWCNT-PtFeOCPc, meaning that the removal of $\mathrm{CO}$ from the EPPGE-PtFeOCPc
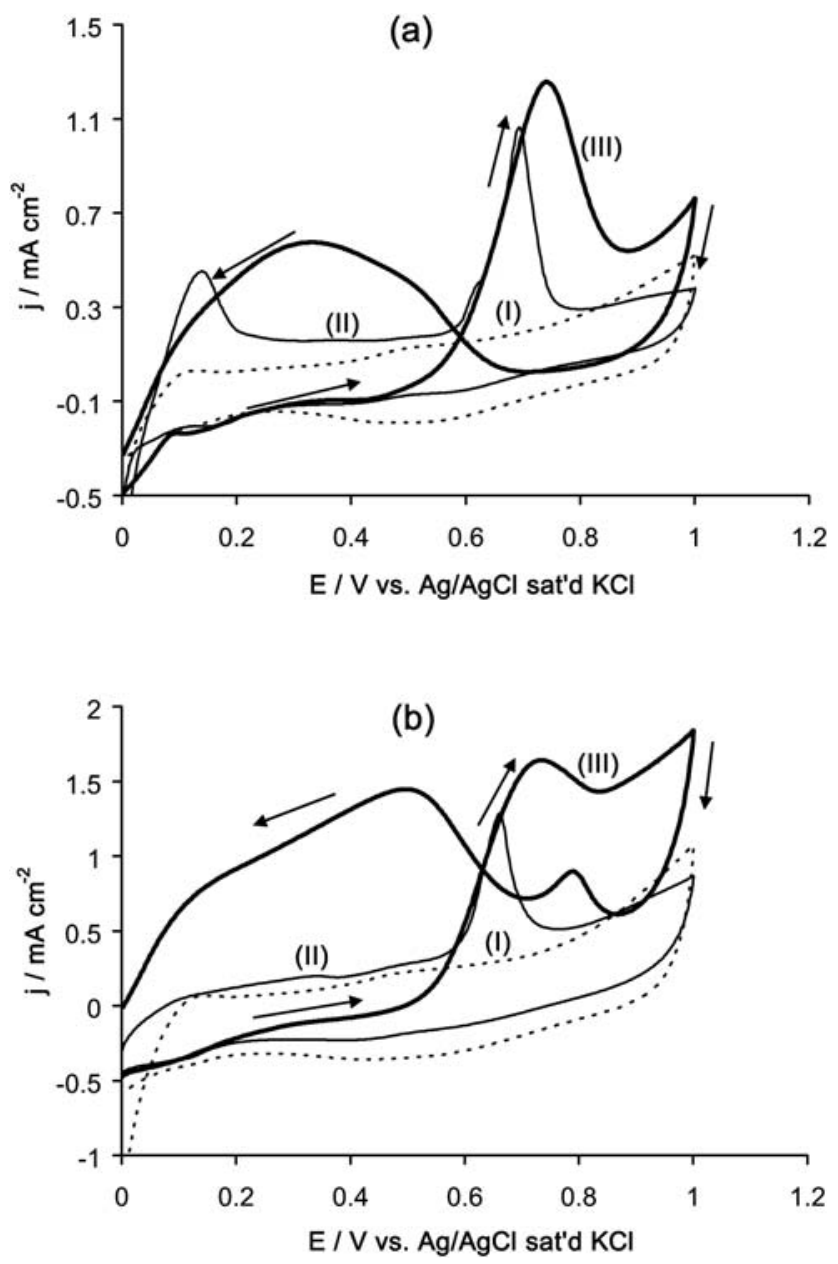

Fig. 12 Comparative cyclic voltammograms of EPPGE-PtFeOCPc (a) and EPPGE-MWCNT-PtFeOCPc (b) electrodes studied in $0.5 \mathrm{M}$ $\mathrm{H}_{2} \mathrm{SO}_{4}$ (I), CO saturated in $0.5 \mathrm{M} \mathrm{H}_{2} \mathrm{SO}_{4}$ (II) and $\mathrm{CO}$ saturated in $0.5 \mathrm{M}$ $\mathrm{H}_{2} \mathrm{SO}_{4}$ and $0.5 \mathrm{M} \mathrm{HCOOH}$ (III). 
electrode will be slightly difficult. ${ }^{82}$ Secondly, from the electrocatalytic waves of (III) in both figures, the ratio of the current density of the forward anodic peak to the reverse anodic peak of 2.18 and 1.12 was obtained for EPPGE-PtFeOCPc and EPPGE-MWCNT-PtFeOCPc, respectively, meaning that EPPGE-MWCNT-PtFeOCPc tolerates $\mathrm{CO}$ poisoning than its EPPGE-PtFeOCPc counterpart.

\section{Conclusions}

A novel platinum-based macrocycle, iron(II) tetrakis(diaquaplatinum)octacarboxyphthalocyanine ( $\mathrm{PtFeOCPc}$ ), was synthesised and characterised. The heterogeneous electron transfer and electrocatalytic properties of this functional material towards the oxidation of formic acid have been explored on a graphite electrode platform pre-modified with or without MWCNTs. The key findings in this work include the following. When compared to other electrodes, the PtFeOCPc supported on a MWCNT platform (MWCNT-PtFeOCPc) exhibits better electrochemical response in terms of: (i) electron transfer towards outer-sphere redox probe, (ii) catalytic rate constant, and (iii) tolerance towards $\mathrm{CO}$ poisoning during formic acid oxidation. Tafel analysis confirmed the porous structure and high electrocatalytic property of the electrode, and suggests that same electrocatalytic mechanism may be operating at all the concentrations studied. Our results suggest that the MWCNT-PtFeOCPc is a promising platform for potential application as an electrocatalyst for direct formic acid fuel cell.

\section{Acknowledgements}

We thank the National Research Foundation (NRF) and CSIR for supporting this work. S.A.M. thanks NRF for the prestigious Nanoflagship PhD bursary and Adamawa State University for study leave and financial support.

\section{References}

1 K. I. Ozoemena and T. Nyokong, J. Chem. Soc., Dalton Trans., 2002, 1806.

2 Z. X. Zhao, K. I. Ozoemena, D. M. Maree and T. Nyokong, Dalton Trans., 2005, 1241.

3 B. Agboola, P. Westbroek, K. I. Ozoemena and T. Nyokong, Electrochem. Commun., 2007, 9, 310.

4 B. Agboola, K. I. Ozoemena, P. Westbroek and T. Nyokong, Electrochim. Acta, 2007, 52, 2520.

5 J. Limson and T. Nyokong, Electroanalysis, 1997, 9, 255.

6 K. I. Ozoemena and T. Nyokong, in Electrochemical Sensors Based on Phthalocyanines and Related Complexes: Encyclopedia of Sensors, ed. C. A. Grimes, E. C. Dickey and M. V. Pishko, American Scientific Publishers, 2006, vol. 3, pp. 157-199.

7 K. I. Ozoemena and T. Nyokong, Electrochim. Acta, 2006, 51, 5131.

8 K. I. Ozoemena and T. Nyokong, J. Electroanal. Chem., 2005, 579, 283.

9 B. O. Agboola and K. I. Ozoemena, Phys. Chem. Chem. Phys., 2008, 10, 2399.

10 M. M. Nicholson, in Phthalocyanine: Properties and Applications, ed. A. B. P. Lever and C. C. Leznof, VCH Publishers, New York, 1993, vol. 3 .

11 J. Simon and P. Bassoul, in Phthalocyanine: Properties and Applications, ed. A. B. P. Lever and C. C. Leznof, VCH Publishers, New York, 1993, vol. 2.

12 I. Rosenthal and E. Ben-Hur, in Phthalocyanine: Properties and Applications, ed. A. B. P. Lever and C. C. Leznof, VCH Publishers, New York, 1993, vol. 1.
13 K. Ozoemena, N. Kuznetsova and T. Nyokong, J. Photochem. Photobiol., A, 2001, 139, 217.

14 K. Ozoemena, N. Kuznetsova and T. Nyokong, J. Mol. Catal. A: Chem., 2001, 176, 29.

15 K. I. Ozoemena and T. Nyokong, Inorg. Chem. Commun., 2003, 6, 1192.

16 B. Agboola, K. I. Ozoemena and T. Nyokong, J. Mol. Catal. A: Chem., 2006, 248, 84.

17 Z. P. Li and B. H. Liu, J. Appl. Electrochem., 2010, 40, 475.

18 N. Sehlotho and T. Nyokong, J. Electroanal. Chem., 2006, 595, 161.

19 S. A. Mamuru and K. I. Ozoemena, Electroanalysis, 2010, 22, 985.

20 K. I. Ozoemena, S. A. Mamuru, T. Fukuda, N. Kobayashi and T. Nyokong, Electrochem. Commun., 2009, 11, 1221.

21 S. A. Mamuru, K. I. Ozoemena, T. Fukuda, N. Kobayashi and T. Nyokong, Electrochim. Acta, 2010, 55, 6367.

22 T.-1. Che, Q.-c. Gao, Y.-g. Cai and J.-s. Zhao, Dianchi, 2008, 38, 183.

23 A. Shigehara, Y. Asai and M. Onishi, Jpn. Kokai Tokkyo Koho, JP 20002216764, 2002.

24 A. T. Chidembo, K. I. Ozoemena, B. O. Agboola, V. Gupta, G. G. Wildgoose and R. G. Compton, Energy Environ. Sci., 2010, 3, 228.

25 B. O. Agboola and K. I. Ozoemena, J. Power Sources, 2010, 195, 3841.

26 A. T. Chidembo and K. I. Ozoemena, Electroanalysis, 2010, DOI: 10.1002/elan.201000290.

27 K. I. Ozoemena, J. Pillay and T. Nyokong, Electrochem. Commun., 2006, 8, 1391.

28 K. I. Ozoemena, D. Nkosi and J. Pillay, Electrochim. Acta, 2008, 53, 2844.

29 J. Zagal, S. Griveau, K. I. Ozoemena, T. Nyokong and F. Bedioui, J. Nanosci. Nanotechnol., 2009, 9, 2201.

30 C. Rice, S. Ha, R. I. Masel, P. Waszczuk, A. Wieckowki and T. Barnard, J. Power Sources, 2002, 111, 83.

31 C. Rice, S. Ha, R. I. Masel and A. Wieckowki, J. Power Sources, 2003, 115, 229.

32 Y. W. Rhee, S. Ha, C. Rice and R. I. Masel, J. Power Sources, 2003, 117,35 .

33 R. Larsen, S. Ha, J. Zakzeski and R. I. Masel, J. Power Sources, 2006, $157,78$.

34 Z. Zhang, X. Zhou, C. Liu and W. Xing, Electrochem. Commun, $2008, \mathbf{1 0}, 131$.

35 S. Wang, N. Kristian, S. Jiang and X. Wang, Electrochem. Commun., 2008, 10, 961.

36 R. Parsons and T. VanderHoot, J. Electroanal. Chem., 1988, 9, 257.

37 J. Y. Lee, P. Strasser and M. Eiswirth, Electrochim. Acta, 2001, 47, 501.

38 M. D. Macia, E. Herrero, J. M. Feliu and A. Aldaz, J. Electroanal. Chem., 2001, 500, 498.

39 S. Kang, J. Lee, J. K. Lee, S.-Y. Chung and Y. Tak, J. Phys. Chem. B, 2006, 110, 7270 .

40 L. J. Zhang, Z. Y. Wang and D. G. Xia, J. Alloys Compd., 2006, 426, 268.

41 A. V. Tripkovic, S. Lj. Gojkovic, K. Dj. Popovic, J. D. Lovic and A. Kowal, Electrochim. Acta, 2007, 53, 887.

42 Q. Yi, A. Chen, W. Huang, J. Zhang, X. Liu, G. Xu and Z. Zhou, Electrochem. Commun., 2007, 9, 1513.

43 Q. Yi, W. Huang, X. Liu, G. Xu, Z. Zhou and A. Chen, J. Electroanal. Chem., 2008, 619-620, 197.

44 C. Qui, J. Zhang and H. Ma, Solid State Sci., 2010, 12, 822.

45 X. Zhou, C. Liu, J. Liao, T. Lu and W. Xing, J. Power Sources, 2008, 179, 481.

46 K. Sakamoto and E. Ohno, Prog. Org. Coat., 1997, 31, 139.

47 J. Liu, A. G. Rinzler, H. Dai, J. H. Hafner, R. Kelley Bradley, P. J. Boal, A. Lu and R. E. Smalley, Science, 1998, 280, 1253.

48 O. V. Dolotova and O. L. Kaliya, Russ. J. Coord. Chem., 2007, 33, 111.

49 G.-C. Zhao, L. Zhang, X.-W. Wei and Z.-S. Yang, Electrochem. Commun., 2003, 5, 825 .

50 J. Qu, Y. Shen, X. Qu and S. Dong, Electroanalysis, 2004, 16, 1444.

51 B. W. Dale, Trans. Faraday Soc., 1969, 65, 331.

52 M. J. Stillman and A. J. Thomson, J. Chem. Soc., Faraday Trans.2, 1974, 70, 790.

53 N. Kobayashi, M. Koshiyama, K. Funayama, T. Osa, H. Shirai and K. Hanabusa, J. Chem. Soc., Chem. Commun., 1983, 913.

54 J. Yang, D. Sung, J. Li, X. Yang, J. Yu, Q. Hao, W. Liu, J. Liu, Z. Zou and J. Gu, Electrochim. Acta, 2009, 54, 6300. 
55 J. Prabhuram, T. S. Zhao, C. W. Wang and J. W. Guo, J. Power Sources, 2004, 134, 1.

56 J. G. Guan, W. Wang, R. Z. Gong, R. Z. Yuan, L. H. Gan and K. C. Tam, Langmuir, 2002, 18, 4198.

57 I. Streeter, G. G. Wildgoose, L. Shao and R. G. Compton, Sens. Actuators, B, 2008, 133, 462.

58 S. A. Mamuru and K. I. Ozoemena, Mater. Chem. Phys., 2009, 114, 113.

59 N. S. Mathebula, J. Pillay, G. Toschi, J. A. Verschoor and K. I. Ozoemena, Chem. Commun., 2009, 3345.

60 D. Nkosi, J. Pillay, K. I. Ozoemena, K. Nouneh and M. Oyama, Phys. Chem. Chem. Phys., 2010, 12, 604.

61 J. Pillay, K. I. Ozoemena, R. T. Tshikhudo and R. M. Moutloali, Langmuir, 2010, 26, 9061.

62 K. I. Ozoemena, N. S. Mathebula, J. Pillay and G. Toschi, Phys. Chem. Chem. Phys., 2010, 12, 345.

63 A. J. Bard and L. R. Faulkner, Electrochemical Methods: Fundamentals and Applications, John Wiley \& Sons, Hoboken, NJ, 2nd edn, 2001.

64 H. H. Girault, Analytical and Physical Electrochemistry, EPFL Press, Lausanne, Switzerland, 2004, ch. 7.

65 F. Seland, R. Tunold and D. A. Harrington, Electrochim. Acta, 2008, 53, 6851.

66 B. E. Kumara Swamy and M. Schell, J. Phys. Chem. B, 2006, 110, 5136.

67 B. Liu, H. Y. Li, L. Die, X. H. Zhang, Z. Fan and J. H. Chen, J. Power Sources, 2009, 186, 62.

68 W. Chen, J. Kim, S. Sun and S. Chen, Langmuir, 2007, 23, 11303.
69 N. W. Maxakato, K. I. Ozoemena and C. J. Arendse, Electroanalysis, 2010, 22, 519.

70 V. Selvaraj, A. Nirmala Grace and M. Alagar, J. Colloid Interface Sci., 2009, 333, 254

71 T. Iwasita, X.-H. Xia, E. Herrero and H.-D. Liess, Langmuir, 1996, 12, 4260.

72 J. Cavalier and S. G. Sun, J. Electroanal. Chem., 1986, 199, 471.

73 M. D. Marcia, E. Herrero and J. M. Feliu, J. Electroanal. Chem., 2003, 25, 554.

74 P. G. Blake and C. Hinshelwood, Proc. R. Soc. London, Ser. A, 1960, 255, 444.

75 M. Zhao, C. Rice, R. I. Masel, P. Waszczuk and A. Wieckowski, J. Electrochem. Soc., 2004, 151, A131.

76 P. K. Shen and C. Xu, Electrochem. Commun., 2006, 8, 184.

77 G. Nurk, H. Kasuk, K. Lust, A. Janes and E. Lust, J. Electroanal. Chem., 2003, 533, 1.

78 W. Chen, J. Kim, L.-P. Xu, S. Sun and S. Chen, J. Phys. Chem. C, 2007, 111, 13452.

79 F. Ye, S. Chen, X. Dong and W. Lin, J. Nat. Gas Chem., 2007, 16, 162.

80 J. Pillay and K. I. Ozoemena, Electrochem. Commun., 2007, 9, 1816.

81 S. E. Creager and T. T. Wooster, Anal. Chem., 1998, 70, 4257.

82 F. Hu, C. Chen, Z. Wang, G. Wei and P. K. Shen, Electrochim. Acta, 2006, 52, 1087.

83 A. N. Gavrilov, E. R. Savinova, P. A. Simonov, V. I. Zaikovskii, S. V. Cherepanova, G. A. Tsirlina and V. N. Parmon, Phys. Chem. Chem. Phys., 2007, 9, 5476. 